\title{
Seeing Double at Memorial University: Two WorldCat Local Usability Studies
}

\author{
Sue Fahey \\ Public Services Librarian \\ Health Sciences Library \\ Memorial University \\ sfahey@mun.ca \\ Shannon Gordon \\ Public Services Librarian \\ Health Sciences Library \\ Memorial University \\ sgordon@mun.ca \\ Crystal Rose \\ Public Services Librarian \\ Ferriss Hodgett Library \\ Memorial University \\ crose@swgc.mun.ca
}

\section{Abstract}

Obtaining user feedback is valuable yet often overlooked; so, when Memorial University Libraries launched OCLC's WorldCat Local (WCL) discovery tool in the fall of 2010, usability testing was a logical next step. The Ferriss Hodgett Library in Corner Brook and the Health Sciences Library in St. John's, two branches each with distinct user groups, conducted unique usability studies to determine how WorldCat Local performed common research tasks. The Health Sciences Library was inspired by the information seeking habits of Memorial University's Faculty of Medicine, School of Nursing and School of Pharmacy. This demographic's heavy reliance on journal literature and known item searching made these users an interesting test group. The Ferriss Hodgett Library, serving an undergraduate Liberal Arts and Sciences population, was interested in the information seeking behavior of new students with little to no experience using library resources. At the local level, evidence obtained as a result of this usability testing will provide guidance into future use of WCL at Memorial University Libraries. On a broader scale, the usability findings are relevant to any library considering a shift to a new discovery tool.

\section{Keywords}

academic library; discovery tool; information seeking; usability; usability testing 


\section{Introduction}

Memorial University (MUN) Libraries consists of four branches supporting the research needs of Memorial University of Newfoundland, the largest university in Atlantic Canada with 17,500 full and part time registered students. The usability studies were conducted at two branches: the Health Sciences Library in St. John's, and the Ferriss Hodgett Library in Corner Brook. These libraries represent the second and third largest branches at MUN Libraries and provide access to over 650,000 electronic books, 160,000 print books, 38,000 electronic journals and 550 print journals. The user population includes undergraduate and graduate students, faculty and staff from Health Sciences and Liberal Arts and Science programs, as well as health practitioners in the Health Sciences Centre teaching hospital.

In August 2010, MUN Libraries launched OCLC WorldCat Local (WCL) as a new discovery tool. WCL is a union catalogue indexing MUN Libraries' collection. WCL also includes 1.5 billion records from thousands of library collections worldwide, and journal articles from aggregators such as ArticleFirst, British Library Inside Serials, Elsevier, ERIC, JSTOR, Medline and OAlster (OCLC). WCL was integrated into the MUN Libraries website as a search box on the homepages of all branch websites (Figure 1).

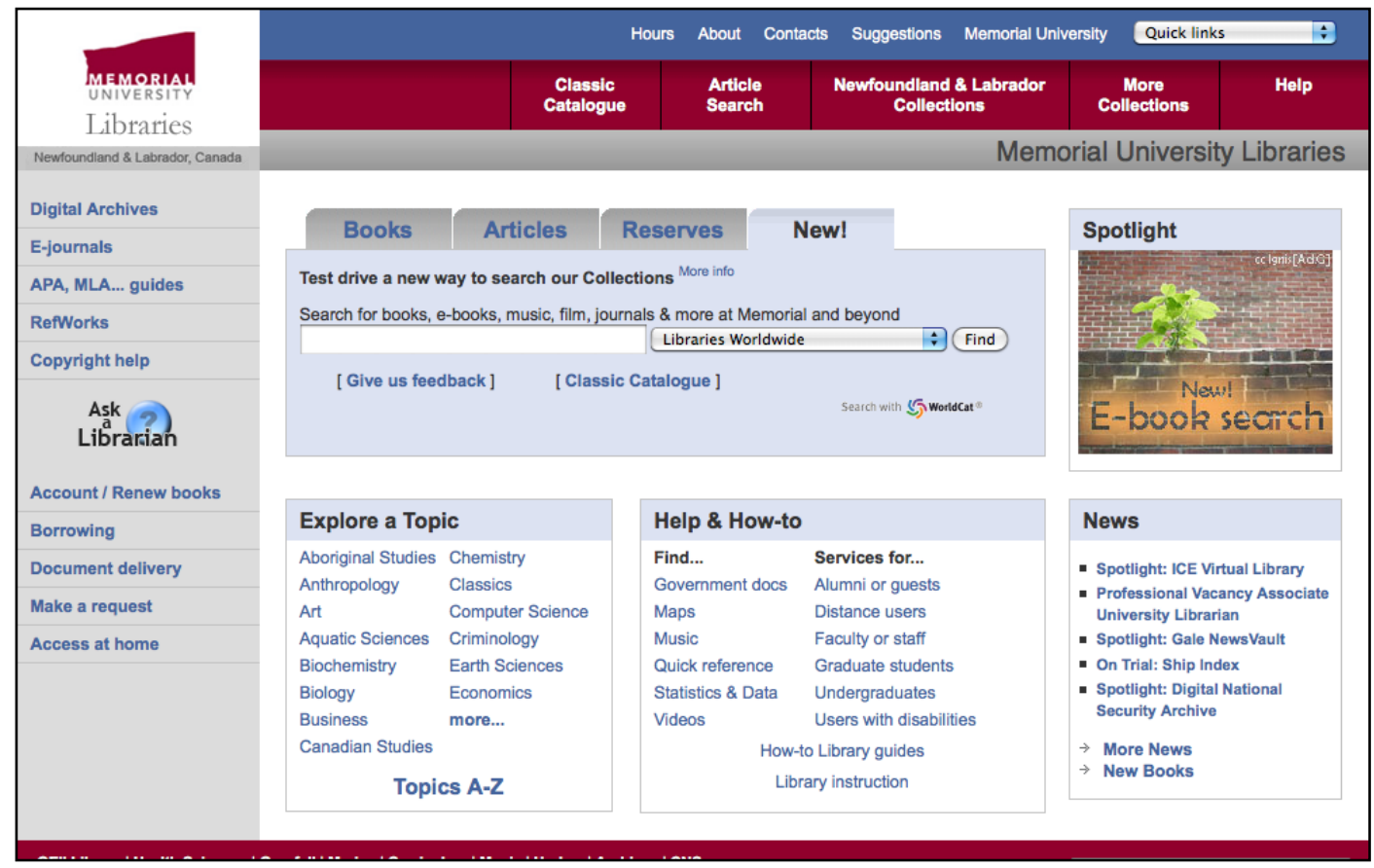

Figure 1: WCL search box on the MUN Libraries website 
At the time of the study, searching WCL was made the default search tab, labeled 'New!', and given the explanation "Test drive a new way to search our Collections Search for books, e-books, music, film, journals \& more at Memorial and beyond." Access to the library collection through WCL became an additional discovery option to the already existing "classic" online library catalogue (CC). MUN Libraries has been using the CC, a Sirsi/Dynix Symphony online library catalogue, since 1996 with the current look and feel being introduced in 2007. The launch of WCL, combined with the continuing existence of the CC, presented an opportunity to conduct usability testing to obtain user feedback on both of these search tools. Although using differing methodologies, both studies tested WCL usability and satisfaction from the local library user perspective and produced remarkably similar results. This article reports the findings of these studies and explores the usability of WCL and the CC in the context of differing methodologies.

\section{The literature}

There have been several recent WCL usability studies conducted in academic environments. These studies tested a diverse group of library users, including undergraduate and graduate students and/or faculty from multiple disciplines with differing search experiences and needs (Thomas and Buck; York St John University JISC LMS Project; Boock, Chadwell and Reese; Ward, Shadle and Mofield) or focused exclusively on sophisticated searchers such as graduate students and faculty (Arcolio and Poe). None have been specific to information seeking habits within the health sciences. Only two studies had users carry out search tasks in both WCL and the library's existing library catalogue (Thomas and Buck; Boock, Chadwell and Reese). Boock, Chadwell, and Reese determined that participants preferred WCL overall, with the most common reason being "the ability to search...materials easily from other institutions...and the ability to find articles," but the existing catalogue was more effective for known title searching (8). Thomas and Buck found that the overall success rates were very similar (659), and that the results of their satisfaction survey were "remarkably similar" for both, with a very small preference for WCL (667). They also noted that "a number of tasks were identified where users were significantly less successful in WCL" including known item searching (668-9).

Similarly, Arcolio and Poe found that participants expressed a preference for WCL and determined that it was an improvement over their existing library catalogue; participants in their study particularly liked the inclusion of journal article content (3). Their study was limited to graduate students and faculty. Ward Shadle and Mofield found that WCL "users were generally successful in finding materials" (18) but did not determine a clear user preference (22-3). The inclusion of journal content in WCL, viewed favorably by participants in some studies, has conversely proved confusing to participants in other studies. Thomas and Buck observed that "this merger of format types within a single set of results caused confusion as the participants did not easily distinguish between books and articles" (669). The York St John University JISC LMS Project also noted that, "alarmingly, some users seem to be unaware of the difference between books, journals and articles" and had "trouble differentiating between the different types of 
material returned in the results" (n. pag.).

In three of the studies, known item searching proved less effective in WCL. In the Thomas and Buck study, users expressed frustration that search results did not seem relevant to the search entered (664), and in the Boock, Chadwell and Reese study, users expressed a preference for known title searching in the existing catalogue. In their report to OSU Libraries they stated that "there are too many known issues for us to feel comfortable providing this to our users without a back-up", meaning the existing catalogue (14). Overall, evidence shows that WCL may be more effective with general subject searches, as participants were typically able to do a successful keyword search for a topic and retrieve articles and books on the subject (Thomas and Buck, 661; York St John University JISC LMS Project).

\section{The usability studies ${ }^{1}$}

\section{Research questions}

As with other disciplines, users of the Health Sciences Library have unique information seeking habits. This demographic relies heavily on journal literature, performs extensive known item searching and regularly uses reserve material. As the interface was still in a beta stage at the time of the study, gathering feedback on the interface was considered valuable. Considering these elements, the Health Sciences study posed two research questions:

1. How well does WCL perform common Health Sciences research tasks?

2. What do study participants think of the WCL interface?

Similarly, the Arts \& Sciences study was interested in the common types of searches performed by typical undergraduate students and in comparing student success in performing those search tasks in WCL and the CC. Three research questions were posed:

1. Would there be a significant difference in the success rates of students using WCL compared to the CC?

2. Were there particular types of searches that would have a higher or lower success rate depending on the catalogue used?

3. What do study participants think of the WCL interface?

${ }^{1}$ Ethics approval was received from Memorial University's Human Investigation Committee, and the Grenfell Campus Ethics Committee in early Fall 2010. The studies commenced shortly thereafter. 


\section{Methodology}

During the sessions, participants were required to read and sign a consent form, complete a background questionnaire, complete search tasks using WCL or the CC and record responses on provided task sheets. The Arts and Sciences participants also completed a post-test questionnaire, with nine questions indicating their opinion on a scale and three open ended questions soliciting comments.

The Health Sciences study used Snagit's video capture feature to record on-screen movements and provided 5 hours of footage; the sessions provided 9 completed task packages and 45 completed tasks. The Arts and Sciences study used Camtasia to record approximately 12 hours of on-screen movements, providing 24 completed task packages and 168 completed tasks.

\section{Participants}

The call for participants for both studies was made through appropriate listservs, websites and posters. Nine Health Sciences individuals participated: 5 from Medicine, 3 from Nursing and 1 from Pharmacy. This included 4 undergraduate students, 2 graduate students, $1 \mathrm{PhD}$ student and 2 faculty members. Likewise, 24 Arts and Sciences students participated: 13 first year students, 6 second year students, 3 third year students, and 2 students from fourth year or above. Both participant groups were judged to be reasonably representative of the population of interest. Each participant received ten dollars for volunteering.

\section{Search tasks}

For the Health Sciences study, five usability scenarios were used, with each scenario including several sub-tasks and sub-questions. The tasks were designed to discover how WCL supported: finding articles on a specific topic, determining access to specific editions of a popular text as well as a required text, determining availability of a known article citation, and searching for known reserve material. Table 1 provides an overview of the usability scenario that participants were required to use for each search task. 


\begin{tabular}{|ll|}
\hline Table 1: Health & Sciences usability scenarios \\
\hline Search task & Scenario \\
search & $\begin{array}{l}\text { You are working on a research paper for a nursing course and } \\
\text { need to find journal articles on this topic: the role of nurses in } \\
\text { palliative care. }\end{array}$ \\
\hline $\begin{array}{l}\text { Known item - } \\
\text { text }\end{array}$ & $\begin{array}{l}\text { Memorial University Libraries owns a copy of the 2010 } \\
\text { publication Compendium of Pharmaceuticals and Specialties, } \\
\text { and you need to confirm a detail in the book. }\end{array}$ \\
\hline $\begin{array}{l}\text { Known item - } \\
\text { article }\end{array}$ & $\begin{array}{l}\text { You are interested in ethical concerns related to surrogacy. } \\
\text { While reading on the topic, you discovered the following article } \\
\text { in a bibliography, and wonder if it is available at the library. }\end{array}$ \\
$\begin{array}{l}\text { Torke, A. M., Simmerling, M., Siegler, M., Kaya, D., \& } \\
\text { Alexander, G. C. (2008). Rethinking the ethical framework for } \\
\text { surrogate decision making: A qualitative study of physicians. } \\
\text { The Journal of Clinical Ethics, 19(2), 110-119. }\end{array}$ \\
\hline $\begin{array}{l}\text { Known item - } \\
\text { reserve }\end{array}$ & $\begin{array}{l}\text { You are taking PHARM4501 and need to look at a book for this } \\
\text { course. You know that it is on Reserve at the Health Sciences } \\
\text { Library. }\end{array}$ \\
\hline $\begin{array}{l}\text { Known item - } \\
\text { text }\end{array}$ & $\begin{array}{l}\text { You are preparing for your MCCQE (Medical Council of Canada } \\
\text { Qualifying Examination) and want to review the thorax. The } \\
\text { citation details for the book you need are: } \\
\text { Vogl, W., Mitchell, A. W. M., Gray, H., \& Drake, R. L. (2010). } \\
\text { Gray's anatomy for students (2nd ed.). Philadelphia, PA: } \\
\text { Churchill Livingstone/Elsevier. }\end{array}$ \\
\hline
\end{tabular}

Health Sciences participants were also asked: 'Have you ever looked for this kind of information before?'; 'Was using WCL to complete this task straightforward?'; and 'What was the most difficult part of completing the task?'. Gathering opinion-based feedback helped gain insight into what the Health Sciences usability group thought of WCL as a research tool.

Likewise, the Arts \& Sciences participants completed seven search tasks, which were recorded using screen-capture software. Ten first year students performed the tasks using WCL, 10 first year students performed the tasks using the CC, and 10 second or third year students performed the tasks using WCL. The participants were not given any instruction or assistance on how to use either catalogue. Table 2 describes the usability scenarios in detail. 


\section{Table 2: Arts \& Sciences usability scenarios}

\begin{tabular}{|ll|}
\hline Search task & Question \\
\hline Access an online journal & $\begin{array}{l}\text { 1a. Do a search for the "Journal of } \\
\text { Adolescent Health". Is this journal } \\
\text { available online? }\end{array}$ \\
\hline Locate print journal & $\begin{array}{l}\text { 1b. Is this journal available in print at the } \\
\text { Ferriss Hodgett Library branch? }\end{array}$ \\
\hline $\begin{array}{l}\text { Known-item Search: Locate a book } \\
\text { by title, and locate call number }\end{array}$ & $\begin{array}{l}\text { 2. Do a search for the 1967 book "The } \\
\text { Ghost in the Machine" by Arthur Koestler. } \\
\text { What is the call number? }\end{array}$ \\
\hline $\begin{array}{l}\text { Author Search: Locate a book by } \\
\text { author, and locate call number }\end{array}$ & $\begin{array}{l}\text { 3a. Do a search for books by the author } \\
\text { Sandra Birdsell. Write down the title and } \\
\text { call number of a book by this author. }\end{array}$ \\
\hline Location information of an item & $\begin{array}{l}\text { 3b. Is this book available at the Ferriss } \\
\text { Hodgett Library branch? }\end{array}$ \\
\hline $\begin{array}{l}\text { Subject Search: Locate a book by } \\
\text { topic }\end{array}$ & $\begin{array}{l}\text { 4a. Do a search on the topic "global } \\
\text { warming". Write down the following } \\
\text { information about a book on that topic: } \\
\text { title, author, publication information, call } \\
\text { number. }\end{array}$ \\
\hline Location information of an item & $\begin{array}{l}\text { 4b. Is this book available at the Ferriss } \\
\text { Hodgett Library branch? }\end{array}$ \\
\hline
\end{tabular}

\section{Limitations}

One limitation of the Health Sciences study was that it only tested WCL, whereas the Arts and Sciences study also tested the CC. This meant that, for the Health Sciences study, it was difficult to conclude whether perceived limitations of WCL were unique to WCL or if they would also be true of the CC if comparative testing had taken place. The limitation of the Arts and Sciences study was that participants could only do searches that were possible in both WCL and the CC, so no usability data could be gathered on article searches. In addition, due to technical difficulties, only seven of the nine recorded sessions from the Health Sciences study could be analyzed. In spite of this, all completed task packages were used for data analysis. 


\section{Results}

As the goal of this article is to compare the findings of both studies, search results will focus only on tasks carried out in both studies: searching for books and journals.

\section{Searching for books - Health Sciences}

Two Health Sciences tasks involved searching for specified editions of popular texts. This included the popular text, Compendium of Pharmaceuticals and Specialties and the required first year Medical text, Gray's Anatomy for Students.

Health Sciences participants were asked to determine which libraries had a 2010 print copy of the Compendium of Pharmaceuticals and Specialties. Figure 2 reveals that only $22 \%$ of participants properly identified the correct location. The majority, $78 \%$, believed that the 2010 text was available at multiple locations, which was incorrect. Despite this, $55 \%$ of participants considered this task to be straightforward. This contrast between performance and perceived success suggests a lack of awareness of the difficulty in interpreting holdings information.

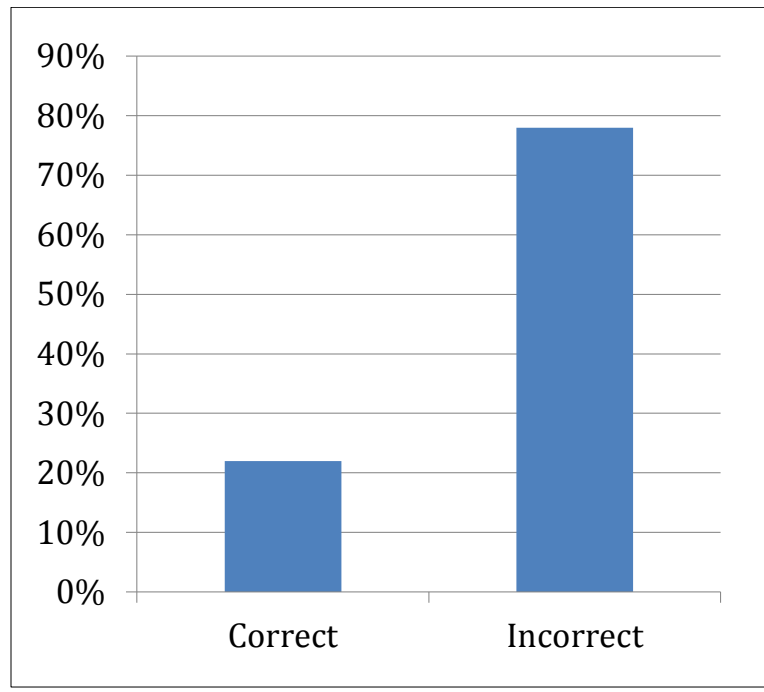

Figure 2: Identifying the location of the 2010 text Compendium of Pharmaceuticals and Specialties

The second Health Sciences book task involved searching for various editions of Gray's Anatomy for Students. As seen in Figure 3, performance was strong: 78\% confirmed the availability of the first edition and $100 \%$ confirmed the availability of the second edition. All members of the group indicated this task to be straightforward. The majority of participants (89\%), had previous experience looking for this kind of information, which likely contributed to their successful completion of this task. Despite this strong performance and the task's self-declared straightforwardness, confusion interpreting holdings information remained, which echoed the performance of the other Health Sciences book search task. 


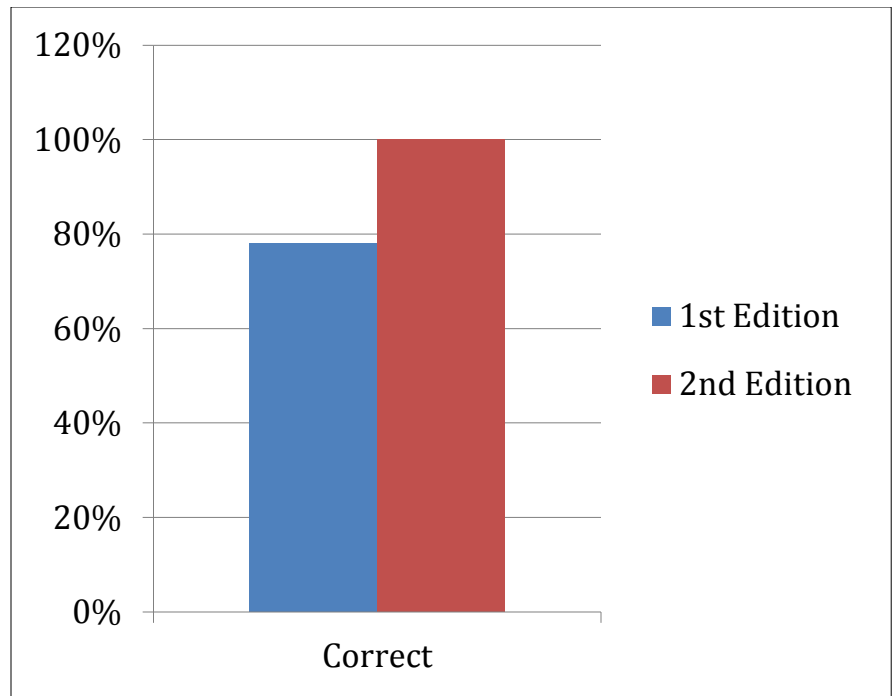

Figure 3: Identifying availability of Gray's Anatomy for Students

Feedback from Health Sciences participants revealed the main challenge to be interpreting availability information. Comments included:

- "Finding the right edition of the resource"

- "Looking for previous editions"

- "I'm not $100 \%$ sure if the book I found was correct"

- "Took a while to figure out what to click to get both types of info--> which library and call numbers"

- "Can't find call numbers!"

\section{Searching for books - Arts \& Sciences}

Five of the tasks in the Arts and Sciences study involved searching for books by title, author or by subject. Participants were first asked to do a "known-item search" for a copy of the 1967 edition of the book The Ghost in the Machine by Arthur Koestler and locate the call number. Regardless of which interface they used, users performed this search task reasonably well. The majority (82\%) of the WCL users and $86 \%$ of the CC users correctly identified the item and call number.

Similarly, when asked to search for a book on the topic "global warming", $100 \%$ of WCL users and $100 \%$ of CC users successfully identified a book and provided the correct item information (title, author, publication information, call number). Participants did have some difficulty with the second part of this task - determining if the item was available at their library - with slight variation between WCL and the CC. The item's location was correctly identified by $76 \%$ of WCL users and $86 \%$ of CC users.

Participants were asked to search for a book by author Sandra Birdsell and identify its call number. This task was accomplished successfully by $100 \%$ of CC users compared to only $76 \%$ of WCL users (Figure 4). When the incorrect responses were analyzed, it was clear that students were having difficulty distinguishing between a book and other types of items (articles, periodicals) in WCL. The other difficulty students encountered in WCL, that did not seem to be problematic in the CC, was determining the call number. 
Students seemed to be confused by some of the other numbers displayed in WCL, such as the OCLC number and the ISBN.

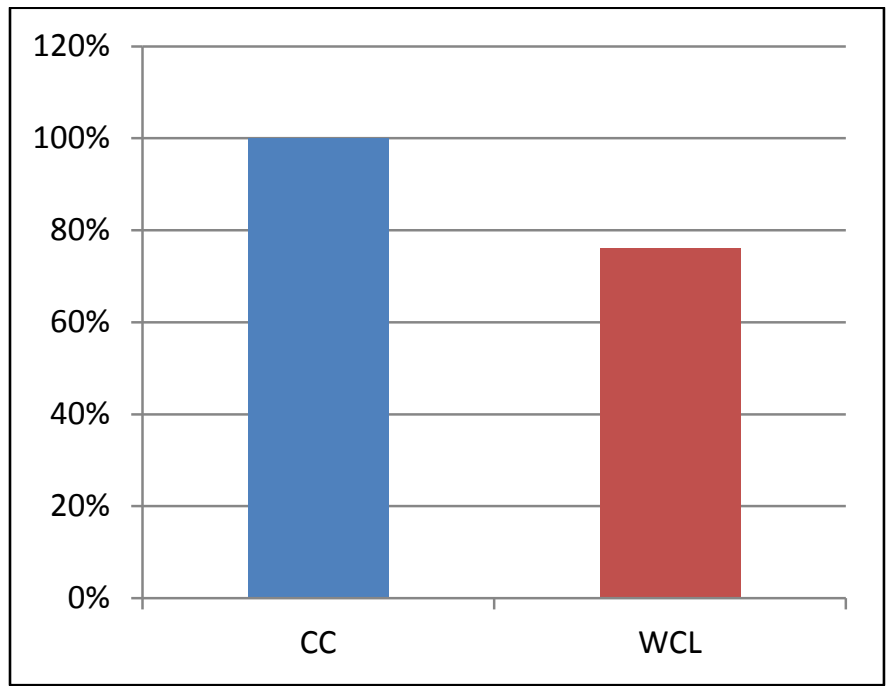

Figure 4: Success rate identifying book by author Sandra Birdsell

In the post-test questionnaire designed to gauge participant opinions about either WCL or the CC, the response to the statement "It was easy to find the call number for a book" showed variation between the user groups; $100 \%$ of CC users "strongly agreed" compared to only $65 \%$ of WCL users. Six percent of WCL users "disagreed" with the statement. Participant perception was consistent with our finding that WCL users had difficulty performing this task.

\section{Searching for journals - Health Sciences}

Health Sciences participants were also asked to determine online and print availability of The Journal of Clinical Ethics. As shown in Figure 5, participants evinced the most success in determining online availability: $89 \%$ correctly identified online availability whereas only $56 \%$ correctly identified print availability.

While the majority confirmed availability, participants acknowledged confusion with determining access. While $67 \%$ indicated previous experience performing this type of research task, only $44 \%$ found it to be straightforward. Video footage showed participants making use of advanced search, limiting their search to MUN Libraries, using the local resolver link and going straight to the CC. 


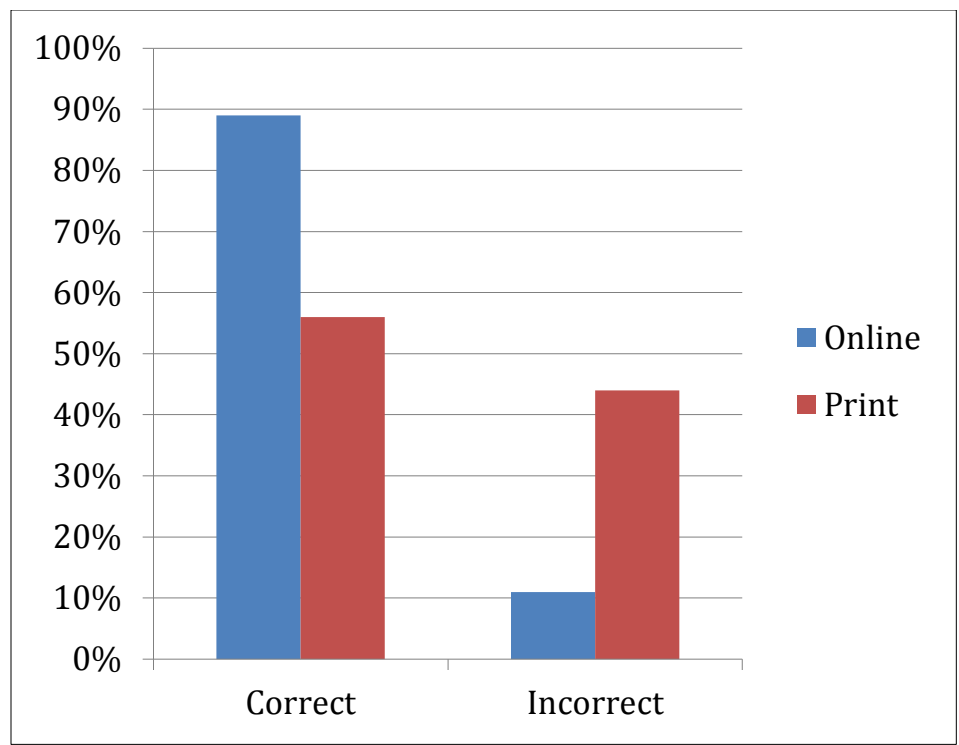

Figure 5: Success rate identifying online and print access to The Journal of Clinical Ethics

As with the Health Sciences book search tasks, participants again expressed frustration with determining access; feedback included:

- "Trying to see if I could get the document online"

- "Finding the closest print copies"

- 'I don't know how to access the article online. 'Get it @ Memorial' doesn't give me a link to the article, just a bunch of useless junk instead!"

- "Looking for the print copy"

- "For looking up if it was available electronically, the get it at Memorial button brought me not to the article"

- "Straight forward"

- "Getting stuck in the catalogue - unsure how to get back to Worldcat without retyping in url"

\section{Searching for journals - Arts \& Sciences}

In the Arts and Sciences study, participants were asked to search for The Journal of Adolescent Health and determine if it was available online and/or in print at the Grenfell Campus branch. Compared to the other search tasks, this task was difficult for both groups; only $65 \%$ of WCL users and $57 \%$ of CC users answered this correctly (Figure 6). These users incorrectly stated that Grenfell did have The Journal of Adolescent Health in print. CC users were either unable to make a distinction between branches or possibly misunderstood the question, indicating simply that it was available in print. The WCL users ended their search on the first page of results which indicated "Libraries that own this item: Memorial University Libraries". They did not click on the item to view branch level holdings. Similarly, they may have misunderstood the question, indicating that the library held the title, although not necessarily the Grenfell branch. 


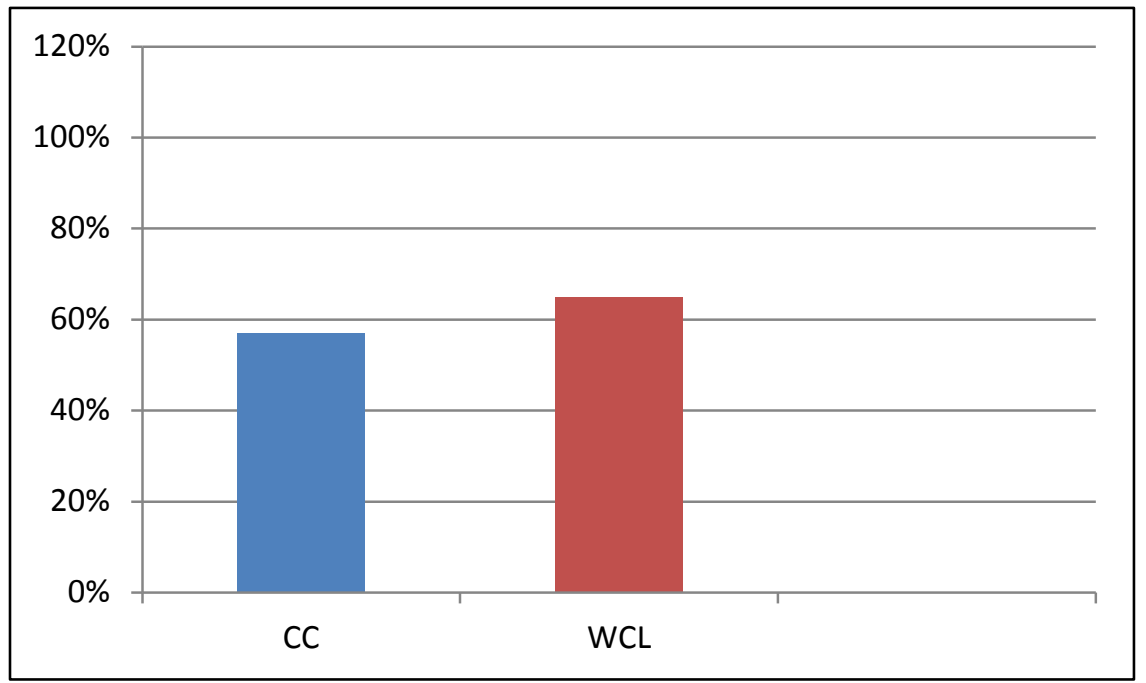

Figure 6: Success rate determining print and/or online availability of The Journal of Adolescent Health

In the Arts and Sciences post-test questionnaire, there was little significant difference between the opinions of CC users and WCL users, with both groups expressing generally positive opinions. Participants had to indicate to what extent they agreed or disagreed with eight statements about the catalogue they used. The majority of both the WCL and the CC users "strongly agreed" with the following five statements:

- "It was easy to find a book (print or electronic) in the Grenfell library"

- "The information I got from the catalogue was relevant"

- "I was able to navigate through the screens easily"

- "The information was presented in a readable format"

- "The information was presented in an uncluttered format"

When asked what they liked most about the library catalogue they used, CC users generally said that it was "easy" $(72 \%)$, particularly in terms of narrowing your search by library (43\%). WCL users similarly used the terms "easy" (47\%), "clear" (12\%), "not confusing" and "simplicity". WCL users liked that the most "relevant" results displayed first (12\%). There were many positive comments about WCL's layout (47\%), which included:

- "Having the book covers shown when searching was helpful"

- "Font...and the way the information was laid out when you clicked on a book

- or articles"

- "All info was formatted in an easy to find manner"

- "The back button does not undo everything! Excellent! Very happy about

- that"

- "Much easier to use than [CC]. Everything is there in that one search"

When asked what they liked least about the library catalogue they used, $43 \%$ of CC users said "nothing", compared to $29 \%$ of WCL users. Some of the CC issues included 
the way search results displayed and finding an item's details. The WCL problems included difficulty narrowing searches or limiting results, difficulty determining if an item was at the student's branch, and difficulty determining if a journal was accessible online. Two WCL users described it as "cluttered", with one writing, "It may be hard to find what I'm looking for with so many options and buttons."

\section{Discussion}

The most interesting discovery was that the findings from both studies were remarkably similar. Specific challenges emerged for participants in both studies: consistent interpretation of citation information, locating call numbers, identifying desired edition, determining availability of print journals, and recognizing item format. Most notably, there were few significant differences between how users performed in WCL compared to the CC, and participants did not show a strong preference for WCL. This is similar to the results obtained by Thomas and Buck, and Ward, et al. The majority of Health Sciences participants indicated a neutral reaction: they neither particularly liked nor disliked WCL. While acknowledging a learning curve, they admitted that this was the reality for all new research databases, not just WCL, and was a reality extending to all things online. In the Arts and Sciences study, the comments and feedback received about both the CC and WCL were generally positive. Being able to search libraries worldwide in WCL was an appealing feature for some users, while others were ambivalent or expressed that they would prefer to search only their library's holdings. This was consistent with Boock, Chadwell and Reese, who found that "catalog preference was influenced by different needs. More participants liked the inclusion of articles... although some preferred to see only what is available at OSU and found additional information confusing" (12).

\section{Conclusion}

Evidence from both studies confirmed that information seeking barriers do exist among library users. The fact that participants in the Arts and Sciences study experienced some of the above difficulties in both the CC and WCL suggests that existing difficulties in the library's catalogue may not necessarily be solved by WCL. A similar observation can be made of the Health Sciences participants. In fact, WCL introduced additional challenges that participants did not encounter in the CC. While WCL is arguably "prettier" than the MUN Libraries existing online catalogue, good looks alone will not resolve issues rooted in information literacy. WCL is not a panacea for the problems users have when searching traditional catalogues. 


\section{Works cited}

Arcolio, Arnold and Felicia Poe. "WorldCat Local at the University of California Usability Testing: Round One, Spring 2008 Findings and Recommendations From the UCOCLC Spring 2008 Assessment Project (Summary Report)." (2008). Web. 21 June 2011

Boock, Michael, Faye Chadwell and Terry Reese. WorldCat Local Task Force Report to LAMP. (27 Mar. 2009). Web. 21 June 2011

OCLC. "Available Content." Worldcat Local: Lists of Content Included. OCLC, n.d. Web. 15 May 2011

Thomas, Bob and Stephanie Buck. "OCLC's WorldCat Local Versus III's WebPAC: Which Interface is Better at Supporting Common User Tasks?" Library Hi Tech 28.4 (2010): 648-671. Web. 21 June 2011

Ward, Jennifer L., Steve Shadle and Pam Mofield. "User Experience, Feedback, and Testing." Library Technology Reports 44.6 (2008):17-23. Web. 21 June 2011

York St John University JISC LMS Project. “JISC LMS Project: Usability Report: A Single Iteration Usability Evaluation of York St John University's implementation of OCLC WorldCat Local." Yocalcat's JISC LMS Blog. N.p., 4 Oct. 2010. Web. 2 Aug. 2011 